\title{
Community pharmacy-based alcohol brief intervention in the UK: significant alcohol consumption reduction in risky drinkers
}

\author{
Natasha Khan ${ }^{1 *}$, Ranjita Dhital ${ }^{2}$, Cate Whittlesea', lan Norman², Peter Milligan³ \\ From International Network on Brief Interventions for Alcohol Problems (INEBRIA) Meeting 2011 \\ Boston, MA, USA. 21-23 September 2011
}

Previous studies have shown that community-pharmacybased screening and brief intervention (SBI) for risky alcohol use is feasible. However, few studies have reported significant reductions in alcohol use following pharmacy-delivered BI. In this study, trained pharmacists $(\mathrm{N}=29)$ at 28 community pharmacies in London, UK, offered BI from February-July 2010. Customers seeking alcohol-related medication and/or advice were targeted. Participating pharmacists used Alcohol Use Disorders Identification Test-Consumption (AUDIT-C) scores ( $\geq 3$ for women and $\geq 4$ for men), a seven-day drinking diary, and feedback on a readiness to change form to identify people with risky drinking and to inform appropriate advice and feedback. One in four community pharmacy customers $(\mathrm{n}=246)$ offered the alcohol BI were initially interested, and half of these $(\mathrm{n}=134,87$ of whom were men) received the intervention. Of the 128 customers whose alcohol use was recorded, $16 \%(\mathrm{n}=21)$ were classified as high-risk drinkers, $56 \%(\mathrm{n}=72)$ as increasingrisk drinkers, and $27 \%(\mathrm{n}=35)$ as low-risk drinkers. Three months following BI, low- and increasing-risk drinkers were contacted by a member of the study team to obtain a post-BI AUDIT-C score and to assess past seven-day alcohol consumption. High-risk drinkers were contacted to ascertain whether they had accessed specialty alcohol services. Seventy-five customers were available for follow-up (response rate, 56\%). Of the high-risk drinkers, $91 \%(\mathrm{n}=10)$ had seen their general practitioner (GP) and/or accessed specialty alcohol services. Increasing-risk drinkers were found to have significantly reduced their weekly consumption (average decrease, 84\%; $\mathrm{p}=$ $0.004)$ and number of drinking days $(\mathrm{p}=0.05)$, however,

${ }^{1}$ Institute of Pharmaceutical Science, King's College London, London, UK Full list of author information is available at the end of the article no significant change in AUDIT-C score was observed. As anticipated, no significant differences in consumption were observed for low-risk drinkers. In this study, community-pharmacy-based alcohol SBI was effective in reducing weekly alcohol use among increasing-risk drinkers and facilitated contact between high-risk drinkers and their GPs and/or specialty alcohol treatment services.

\section{Author details}

${ }^{1}$ Institute of Pharmaceutical Science, King's College London, London, UK. ${ }^{2}$ Division of Health and Social Care Research, King's College London, London, UK. ${ }^{3}$ School of Biomedical and Health Sciences, King's College London, London, UK.

Published: 9 October 2012

doi:10.1186/1940-0640-7-S1-A55

Cite this article as: Khan et al:: Community pharmacy-based alcohol brief intervention in the UK: significant alcohol consumption reduction in risky drinkers. Addiction Science \& Clinical Practice 2012 7(Suppl 1):A55.

Submit your next manuscript to BioMed Central and take full advantage of:

- Convenient online submission

- Thorough peer review

- No space constraints or color figure charges

- Immediate publication on acceptance

- Inclusion in PubMed, CAS, Scopus and Google Scholar

- Research which is freely available for redistribution
C Biomed Central

() 2012 Khan et al; licensee BioMed Central Ltd. This is an Open Access article distributed under the terms of the Creative Commons Attribution License (http://creativecommons.org/licenses/by/2.0), which permits unrestricted use, distribution, and reproduction in any medium, provided the original work is properly cited. 